\title{
Effect of Antenatal Mental Health Disorder on Fetal Growth: A Systematic Review
}

\author{
Rina Tri Handayani, Aris Widiyanto, Joko Tri Atmojo, Catur Setyorini
}

School of Health and Sciences Mamba'ul Ulum, Surakarta

\section{ABSTRACT}

Background: Maternal mental disorders during pregnancy are associated with a range of adverse health outcomes for infants. Recent studies indicate the possible mechanism of maternal mental health disorders associated with fetal development through programming effect. This study aimed to systematically review the effect of antenatal mental health disorders on fetal growth.

Subjects and Method: This was a systematic review. The articles were selected from PsycINFO, Medline, Web of Science, Embase, and PubMed journal databases published from July to September 2018. The keywords for this review included maternal mental health AND fetal growth, postpartum depression AND fetal growth, maternal mental health AND fetal growth AND review. As many as 11 articles were selected for this study from 575 articles.

Results: Maternal mental health during pregnancy was associated with fetal head circumference growth through 2 mechanism: (1) Increased maternal stress response modifies neuro- endocrine function, which included changes in cortisol regulation, adrenocorticotropic, adrenaline and noradrenaline hormones levels; and (2) Decreased 11 $\beta$-hydroxysteroid dehydrogenase (11 $\beta$-HSD2) enzyme regulation in placenta. It decreased11 $\beta$-HSD2 level, increased fetal glucocorticoids circulation, and affected on fetal head growth restriction.

Conclusion: Maternal mental health during pregnancy is associated with fetal head circumference growth restriction.

Keywords: maternal mental health, fetal head circumference, growth, systematic review

\section{Correspondence:}

Rina Tri Handayani. School of Health Sciences Mamba'ul 'Ulum, Surakarta, Jl. Ring Road Utara, Tawangsari, Mojosongo, Jebres, Surakarta, Central Java. Email: trihandayanirina@gmail.com: 085642224141

Cite this as:

Handayani RT, Widiyanto A, Atmojo JT, Setyorini C (2020). Effect of Antenatal Mental Health Disorder on Fetal Growth: A Systematic Review. J Matern Child Health. 5(2): 147-153.

https://doi.org/10.26911/thejmch.2020.05.02.04

(i) (2) Journal of Maternal and Child Health is licensed under a Creative Commons Attribution-Non Commercial-Share Alike 4.o International License.

\section{BACKGROUND}

Psychological disorders have been reported as a major complication of pregnancy. Postpartum depression (PPD) is one of the main psychological disorders (Lewis, Austin and Galbally, 2016). PPD includes major and minor depression which affects at least 14.5\% (one in seven women) in the first three months of their postpartum with a prevalence that rises to $59 \%$ in the post-partum population in large cities (Gaynes et al., 2005). In addition, anxiety disorders during pregnancy have a higher prevalence than in the postpartum period about $50 \%$ of women with symptoms of PPD also experience depression or anxiety during their pregnancy (Bennett et al., 2004).

Studies report that anxiety or stress during pregnancy have a prevalence of around $13 \%$ in the second trimester and $22 \%$ in the first trimester. Depressive disorders include several diagnostic subtypes' namely major depression (MDD) and dysthymia disorders (dysthymia) which are di-vided into chronic 
and persistent dysthymia. Anxiety disorders also consist of various subtypes including chronic anxiety disorders that are characterized by concerns about daily life, social anxiety or specific phobias (American Psychiatric Association, 2013). Previous studies have shown high levels of comorbidity between antenatal mental disorders that have the potential to cause mental disorders in fetal development (Howard et al., 2014).

Mothers with poor mental health during pregnancy tend to give birth to babies with low preterm birth weights, and growth disorders (Lewis et al., 2016). Growth disturbance in this case is caused by adaptation results from placental and hypoxic-ischemic insufficiency. Symptoms that occurred clinically include reduced Doppler pulsation, biometric reduction in the abdominal circumference (AC). Thus, as the brain grows, an asymmetrical growth pattern is reflected in the head circumference (HC)/AC ratio (Baschat, 2011). The purpose of this study was to review systematically the effects of antenatal mental health disorders on fetal growth.

\section{SUBJECTS AND METHOD \\ 1. Study Design}

This systematic review was based on the preferred reporting items for systematic reviews and Meta-analyzes (PRISMA) guidelines (Liberati et al., 2009). The study was conducted from July to September 2018. A systematic review was carried out by searching for articles from PsycINFO, Medline, Web of Science, Embase and Scopus. Keywords to search for this article include: maternal mental health AND fetal growth, postpartum depression AND fetal growth, maternal mental health AND fetal growth AND review.

\section{Inclusion and Exclusion Criteria}

Inclusion criteria for articles were cohort studies, article reviews, and clinical reviews. Fetal growth is measured during pregnancy through ultrasonography. Maternal mental health included one or more depressions, anxiety and stress measured during pregnancy using a validated instrument. The exclusion criteria were cross-sectional, metaanalysis, case-control, and systematic review study. Fetal growth that measured without using ultrasonography was excluded in this study.

\section{Data Extraction}

A total of 575 articles were collected from PsycINFO, Medline, Web of Science, Embase and Scopus databases using Mendeley program. The articles selected using Preferred Reporting Items for Systematic Reviews and Meta-Analyses (PRISMA) method. A total of 11 articles were included for this study.

\section{RESULTS}

After removing duplication and applying exclusion criteria and examining the full text article carefully, finally 11 articles were included for further discussion.

\section{11 $\beta$-hydroxysteroid dehydrogenase (11 $\beta$-HSD)}

11 $\beta$-hydroxysteroid dehydrogenase (11 $\beta$-HS-

$D)$ is a key enzyme for glucocorticoid metabolism (GC), there are two types of $11 \beta-\mathrm{HSD}$ which are 11 $\beta$-HSD1 and 11 $\beta$-HSD2 (Ni et al., 2018). $11 \beta$-HSD1 is an enzyme that is expressed in the liver, testes, ovaries, lungs, and placenta. 11 $\beta$-HSD1changes 11-ketoglucocorticoid inert biologically (cortisone, 11dehydrocorticosterone) to 11-active hydroxiglucocorticoids (cortisol, corticosterone) (Thompson et al., 2004).

In the human placenta, $11 \beta$ HSD1 located in the decidua where it guarantees the availability of active GCto maintain immunosuppressive effects that function for implantation of blastocysts and immunological tolerance to tissues (Quinkler et al., 2001).

$11 \beta$-HSD2 is expressed in mineralocorticoid target tissues, such as the kidneys, salivary glands, ileum, distal colon, and placenta (Ni et al., 2018). In humans, 11 $\beta-H S D 2$ 
catalyzes inactive 11-oxo and converts cortisol to an inactive GC, cortisone. In the human placenta, $11 \beta$-HSD2 expressed selectively in syncytiotrophoblasts which function to block more than $5 \sim 10$ times the maternal GC into the fetal blood circulation, (Achard et al., 2006). These enzymes play a role in the process of fetal development and will be discussed later.

A large number of epidemiological studies showed that pregnancy complications cause intrauterine growth restriction (IUGR), low birth weight and premature birth. Among the complications pregnancy, there was excessive fetal exposure to GC due to psychological disorders in the form of maternal stress.
Increased GC levels in intrauterine fetal circulation are controlled by placental glucocorticoids. Usually, $11 \beta$-HSD2 in the placental syncytiotrophoblast layer catalyzes the mother's active cortisol into inactive cortisone, blocking the entry of cortisol into the fetus (Wächter et al., 2009). However, when maternal GC levels increase beyond the placental capacity of $11 \beta \mathrm{HSD} 2$ for GC inactivation, this pathological condition impaired placental function (placental insufficiency) and can cause excessive fetal exposure to GC (Das and Sysyn, 2004). Excessive intrauterine exposure to GC induces IUGR, hyperglycemia and hyperten-sion in adult children (Seckl and Holmes, 2007).

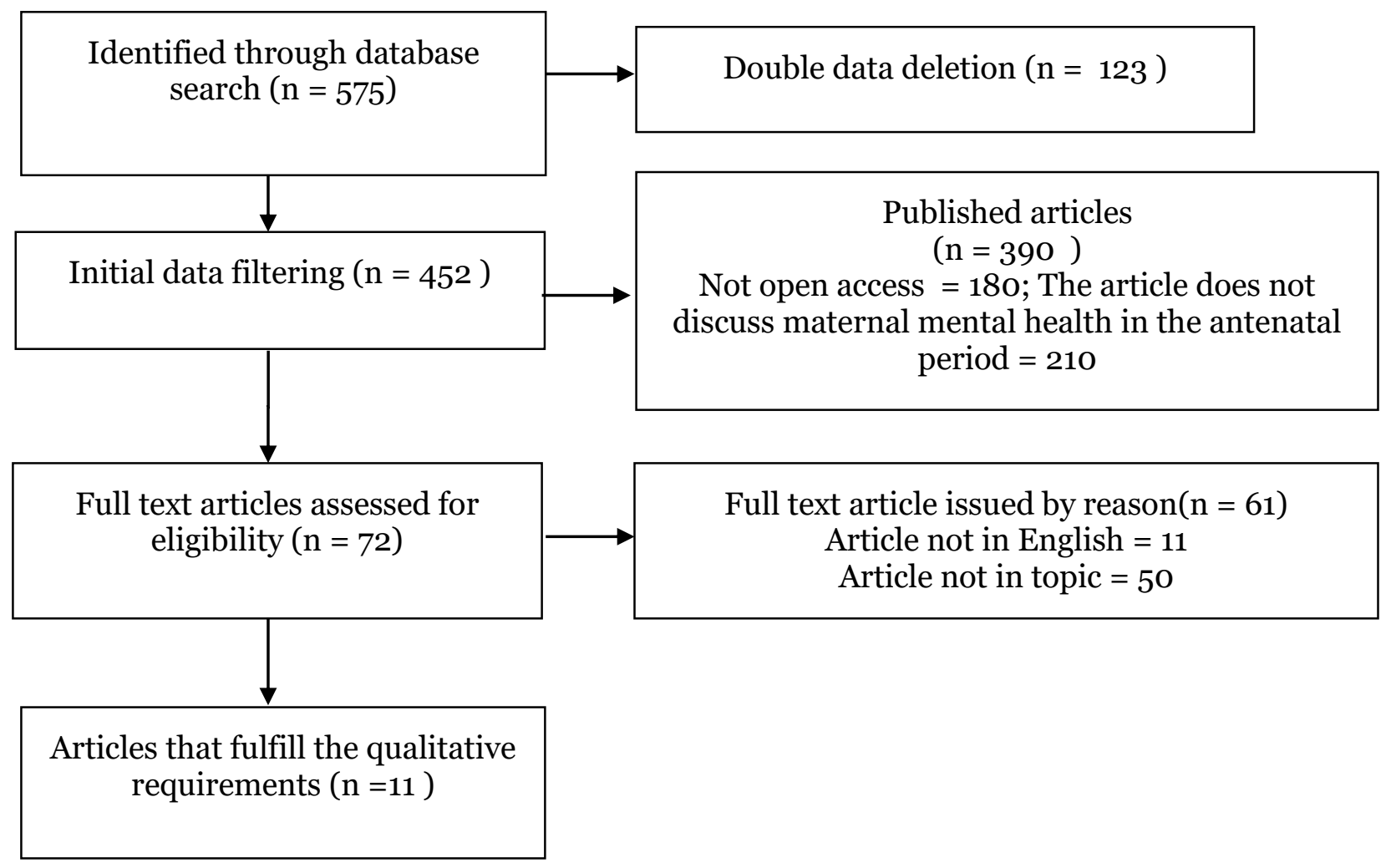

Figure 1. PRISMA Flow Diagram 


\section{Increased response to maternal stress hormones and growth dis- orders}

Maternal psychological disorders accompanied by metabolic and functional changes can affect the fetal development. Psychological disorders during pregnancy cause autonomic changes, maternal circadian rhythm disorders, and changes in behavior that can affect the mother's diet and lifestyle (Lewis et al., 2015).

Such physiological changes can affect the availability of oxygen, glucose to the fetus, interfere with placental endocrine function, induce fetal oxidative stress, and reduce fetal Insulin-like Growth Factor (IGF I and IGF II) which directly regulate fetal development and growth (Lewis et al., 2015).

Various mechanisms by which maternal mental disorders can affect fetal development were associated with increased maternal stress hormones such as cortisol, adrenocorticotropic hormone (ACTH) and adrenaline (Seth et al., 2015).

Specific mechanisms which maternal mental disorders may affect fetal development include: First, maternal psychological pressure was often (but not always) related to modifications in neuroendocrine function, because an increase in maternal stress response caused changes in cortisol regulation, changes in adrenocorticotropic levels, adrenaline, and noradrenalin (Diego et al., 2006). Both increased maternal glucocorticoid circulation throughout pregnancy and release of the hormone corticotropin (CRH) in midpregnancy were also associated with prenatal depression (Seng et al., 2010).

A number of studies, both animal and human, have shown that an increase in the maternal hypothalamic pituitary (HPA) and the sympathetic nervous system caused a decrease in blood supply to the uterine blood vessels, this can reduce fetal insulin levels (Lewis et al., 2016).
This mechanism can interfere with fetal nerve development, reduce density and function of brain cells. It is possible that these processes result not only in intrauterine growth restriction or preterm birth but may also have a long-term effect on fetal mental health through the fetal HPA axis (increase or blunt cortisol response, increased $\mathrm{CRH}$, changes in the sympathetic nervous system and cardiovascular function) (Wu et al., 2012).

In addition, the relationship between maternal mental health and fetal development that may have mechanical implications was the use of antidepressants by pregnant women who were depressed and anxiety the effect of using anti-depressants during pregnancy was also important to fetal growth (Lee et al., 2007).

\section{Decreased regulation of the enzyme 11 $\beta$-hydroxysteroid dehydrogenase (11/-HSD2) in the placenta}

The placenta has function as a temporary endocrine structure, which regulated the transfer of nutrients to the fetus and protects them from the effects of maternal glucocorticoid growth inhibitors. A decrease in 11HSD2 placenta would increase fetal glucocorticoid circulation and have an impact on fetal development including head circumference, fetal HPA shaft development and fetal hormonal programming (Lewis et al., 2015).

The neuroendocrine aspect of the stress response that can lead to stunted fetal development has long-term implications for susceptibility to various cognitive and emotional disorders, especially depression, anxiety, and mental health conditions. This mechanism explained the level of expression of 11-HSD2 in the placenta directly affected by the circulation of maternal stress hormones.

\section{DISCUSSION}

Fetal growth is a complex process governed by various factors including maternal and 
fetal genetics, maternal nutrition that determines the availability of nutrients and oxygen for the fetus, placental vascular dysfunction, but maternal psychological health conditions are also related to the interaction of the placental system.

Maternal mental health during pregnancy was associated with limiting growth in fetal head circumference. Through various mechanisms including: increased glucocorticoids (GC) and $11 \beta$-HSD2, changes in the regulation of the mother's cortisol, adrenocorticotropic, adrenaline, noradrenaline, release of corticotropin hormone (CRH) increased hypothalamic pituitary (HPA) and increased pressure on the sympathetic nervous system have been studied as a corticotropin hormone (CRH) the onset of placental insufficiency.

This placental insufficiency caused a decrease in the availability of oxygen, glucose to the fetus, interferes with placental endocrine function, induces fetal oxidative stress, and reduced fetal insulin circulation such as growth factors (IGF I and IGF II) which further disrupt fetal development and growth.

Findings from the current review highlight the role of maternal anxiety during pregnancy as a major exposure to fetal developmental disorders. The review found consistent evidence for an association between maternal anxiety and decreased fetal head growth. This finding was important because it showed that maternal anxiety and psychological disorders in pregnancy was not only have an impact on children's behavior problems.

Anxiety and stress that can be detected early in pregnancy, which may certainly make an important difference to the fetus, both from physical and mental development. Therefore, assistance, classes of pregnant women, and various psychological handling activities during pregnancy and post pregnancy became important to note.

\section{AUTHOR CONTRIBUTION}

Aris Widiyanto, Rina Tri Handayani, and Joko Tri Atmojo, collected and examined the articles, and wrote the systematic review, with equal contribution.

\section{CONFLICT OF INTEREST}

There is no conflict of interest in this study.

\section{FUNDING AND SPONSORSHIP}

This study was self-funded.

ACKNOWLEDGEMENT

We would like to thankful PsycINFO, Medline, Web of Science, Embase and Scopus databases for providing great articles for us.

\section{REFERENCE}

Achard V, Boullu C S, Desbriére R, Grino M (2006). Perinatal programming of central obesity and the metabolic syndrome: Role of glucocorticoids. Metab Syndr Relat Disord. 4(2): 129-37. https://doi.org/10.1089/met.2006.4.129

American Psychiatric Association (2013) Diagnostic statistical manual of mental disorders. Am J Psychiatry. https://doi.org/10.1176/appi.books.9780890 425596

Baschat AA (2011). Neurodevelopment following fetal growth restriction and its relationship with antepartum parameters of placental dysfunction. Ultrasound Obstet Gynecol. 37(5): 501-14. https://doi.org/10.1002/uog.9008

Bennett H, Einarson A, Taddio A, Koren G, Einarson TR (2004). Prevalence of depression during pregnancy: Systematic review. Obstet Gynecol. 103(4): 698-709.https://doi.org/10.1097/01.aog.0000116689.75396.5f

Das UG, Sysyn GD (2004). Abnormal fetal growth: Intrauterine growth retardation, small for gestational age, large for gestational age. Pediatr Clin N Am. 51(3): 639-54. https://doi.org/10.1016- 
Handayani et al./Effect of Antenatal Mental Health Disorder on Fetal Growth: A Systematic Review

/j.pcl.2004.01.004

Diego MA, Jones NA, Field T, Hernandez RM, Schanberg S, Kuhn C, Gonzalez GA (2006). Maternal psychological distress, prenatal cortisol, and fetal weight. Psychosom Med. 68(5): 74753. https://doi.org/10.1097/01.psy.oo$00238212.21598 .7 \mathrm{~b}$

Gaynes BN, Gavin N, Meltzer-Brody S, Lohr KN, Swinson T, Gartlehner G, Brody S, Miller WC (2005). Perinatal depression: prevalence, screening accuracy, and screening outcomes. Evidence report/technology assessment (Summary). (119): 1-8. https://www.ncbi.nlm. nih.gov/pubmed/?term=10.1037\%2Fe4 39372005001

Howard LM, Molyneaux E, Dennis CL, Rochat T, Stein A, Milgrom J (2014). Nonpsychotic mental disorders in the perinatal period. The Lancet. 384(9956): 1775-88. https://doi.org/10.1016/so140-6736(14)61276-9

Lee AM, Lam SK, Sze ML, Stephanie MC, Catherine SY, Chui HW, Fong DYT (2007). Prevalence, course, and risk factors for antenatal anxiety and depression. Obstet Gynecol. 110(5): 110212. https://doi.org/10.1097/o1.aog.oo00287065.59491.70

Lewis A, Austin E, Knapp R, Vaiano T, Galbally $M$ (2015). Perinatal Maternal Mental Health, Fetal Programming and Child Development. Healthcare, 3(4): 1212-1227. https://doi.org/10.3390/healthcare3041212

Lewis AJ, Austin E, Galbally M (2016). Prenatal maternal mental health and fetal growth restriction: a systematic review. J Dev Orig Health Dis. 7(04): 416-428. https://doi.org/10.1017/s2040174416000076

Liberati A, Altman DG, Tetzlaff J, Mulrow C, Gotzsche PC, Ioannidis JPA, Clarke M (2009). The PRISMA statement for re- porting systematic reviews and metaanalyses of studies that evaluate healthcare interventions: explanation and elaboration. Bmj. 339(1): b270o-b2700. https://doi.org/10.1136/bmj.b270o

NiL, Pan, Yibin T, Chao X, Wenyi W, Ximei Z, Chaochun (2018). Antenatal exposure to betamethasone induces placental 11 $\beta$-hydroxysteroid dehydrogenase type 2 expression and the adult metabolic disorders in mice. PLoS ONE, 13(9): 1-15. https://doi.org/10.1371/journal.pone.0203802

Quinkler M, Oelkers W, Diederich S (2001). Clinical implications of glucocorticoid metabolism by $11 \beta$-hydroxysteroid dehydrogenases in target tissues. Eur $\mathrm{J}$ Endocrinol. 144(2): 87-97. https://doi.org/10.1530/eje.0.1440087

Seth S, Lewis AJ, Saffery R, Lappas M, Galbally $M$ (2015). Maternal prenatal mental health and placental 11 $\beta$-HSD2 gene expression: Initial findings from the mercy pregnancy and emotionalwellbeing study. Int J Mol Sci. 16(11): 27482-96. https://doi.org/10.3390/ijms161126034

Seckl JR, Holmes MC (2007). Mechanisms of disease: Glucocorticoids, their placental metabolism and fetal "programming" of adult pathophysiology. Nat Clin Pract Endoc. 3(6):479-88. https://doi.org/ 10.1038/ncpendmeto515

Seng JS, Rauch SAM, Resnick H, Reed CD, King AL, Lisa K, McPherson M (2010). Exploring posttraumatic stress disorder symptom profile among pregnant women. J Psychosom Obstet Gynaecol. 31(3): 176-87.https://doi. org/10.3109/0167482x.2010.486453

Thompson A, Han VKM, Yang K (2004). Differential expression of $11 \beta$-hydroxysteroid dehydrogenase types 1 and 2 mRNA and glucocorticoid receptor protein during mouse embryonic develop- 
Handayani et al./Effect of Antenatal Mental Health Disorder on Fetal Growth: A Systematic Review

ment. J Steroid Biochem. 88(4-5): 367-375. https://doi.org/10.1016/j.jsbmb.2003.12.014

Wächter R, Masarik L, Bürzle M, Mallik A, Von Mandach U (2009). Differential expression and activity of $11 \beta$-hydroxysteroid dehydrogenase in human placenta and fetal membranes from pregnancies with intrauterine growth res- triction. Fetal Diagn Ther. 25: 328335. https://doi.org/10.1016/j.jsbmb.2003.12.014

Wu G, Imhoff-Kunsch B, Girard AW (2012). Biological mechanisms for nutritional regulation of maternal health and fetal development. Paediatr Perinat Epidemiol. 26(1): 4-26. https://doi. org/10.1111/j.1365-3016.2012.01291.x 